\title{
MicroRNA-449a regulates the progression of brain aging by targeting SCN2B in SAMP8 mice
}

\author{
YA-XIN TAN ${ }^{*}$, YING HONG ${ }^{2 *}$, SHUI JIANG ${ }^{2 *}$, MIN-NAN LU ${ }^{3 *}$, SHAN LI $^{1}$, BO CHEN $^{3}$, \\ $\mathrm{LI} \mathrm{ZHANG}^{4}$, TAO HU ${ }^{2}$, RUI MAO ${ }^{5}$, RONG MEI ${ }^{6}$ and YAN-BIN XIYANG ${ }^{1}$ \\ ${ }^{1}$ Institute of Neuroscience, Basic Medical College, Kunming Medical University, Kunming, Yunnan 650500; \\ ${ }^{2}$ Department of Laboratory Medicine, The Third People's Hospital of Yunnan Province, Kunming, Yunnan 650011; \\ ${ }^{3}$ Science and Technology Achievement Incubation Center; ${ }^{4}$ Editorial Department of Journal of \\ Kunming Medical University; ${ }^{5}$ School of Stomatology, Kunming Medical University, Kunming, Yunnan 650500; \\ ${ }^{6}$ Department of Neurology, The First People's Hospital of Yunnan Province, Kunming, Yunnan 650032, P.R. China
}

Received September 11, 2019; Accepted January 29, 2020

DOI: $10.3892 /$ ijmm.2020.4502

\begin{abstract}
Our previous study demonstrated that the expression of sodium channel voltage-gated beta 2 (SCN2B) increased with aging in senescence-accelerated mouse prone 8 (SAMP8) mice, and was identified to be associated with a decline in learning and memory, while the underlying mechanism is unclear. In the present study, multiple differentially expressed miRNAs, which may be involved in the process of aging by regulating target genes, were identified in the prefrontal cortex and hippocampus of SAMP8 mice though miRNA microarray analysis. Using bioinformatics prediction, SCN2B was identified to be one of the potential target genes of miR-449a, which was downregulated in the hippocampus. Previous studies demonstrated that miR-449a is involved in the occurrence and progression of aging by regulating a variety of target genes. Therefore, it was hypothesized that miR-449a may be involved in the process of brain aging by targeting SCN2B. To verify this hypothesis, the following experiments were conducted: A reverse transcription-quantitative polymerase chain reaction assay revealed that the expression level of miR-449a was significantly decreased in the prefrontal cortex and hippocampus of 12-month old SAMP8 mice; a dual-luciferase reporter assay verified that miR-449a regulated SCN2B expression by binding to the 3'-UTR 'seed region'; an anti-Ago
\end{abstract}

Correspondence to: Dr Yan-Bin Xiyang, Institute of Neuroscience, Basic Medical College, Kunming Medical University, 1168 West Chunrong Road, Yuhua Avenue, Chenggong, Kunming, Yunnan 650500, P.R. China

E-mail: xiyang_neuro@126.com

${ }^{*}$ Contributed equally

Key words: brain aging, microRNA-449a, sodium channel voltage-gated beta 2 , hippocampal neurons, senescence-accelerated mouse prone 8 co-immunoprecipitation combined with Affymetrix microarray analyses demonstrated that the target mRNA highly enriched with Ago-miRNPs was confirmed to be SCN2B. Finally, overexpression of miR-449a or inhibition of SCN2B promoted the extension of hippocampal neurons in vitro. The results of the present study suggested that miR-449a was downregulated in the prefrontal cortex and hippocampus of SAMP8 mice and may regulate the process of brain aging by targeting SCN2B.

\section{Introduction}

Brain senescence is a major risk factor for most human diseases (1). It commonly leads to cognitive impairment and several neurological and neurodegenerative diseases, such as dementia, including Alzheimer's disease (AD), Parkinson's disease and vascular dementia. It was previously demonstrated that $26.9 \%$ of the total Chinese population will be aged $>65$ years by 2050 , placing China among the countries with the highest proportion of aged individuals worldwide (2). However, the mechanisms underlying brain aging remain elusive, and effective prevention methods are required.

Sodium channel voltage-gated beta 2 (SCN2B), an aging-associated gene (3), is expressed in the central nervous system and in cardiac tissue (4). Previous data demonstrated that $\mathrm{SCN} 2 \mathrm{~B}$ is involved in maintaining the normal physiological functions of the prefrontal cortex and hippocampus, and may be associated with the decline of aging and memory in the prefrontal cortex of senescence-accelerated mouse prone 8 (SAMP8) (5). Compared with the control group, the results from the present study suggested that the expression of SCN2B in the prefrontal cortex of SAMP8 mice increased with increases in age, which is the basis of dysfunction. These increases are accompanied by dysfunction (5). It was also identified that the downregulation of SCN2B by $60.68 \%$ significantly improved hippocampus-dependent spatial cognitive memory in aged transgenic mice, and increased the synaptic excitability of the hippocampus by increasing the number of spinous processes in hippocampal neurons (6). Furthermore, it 
was also observed that sodium current density in hippocampal neurons and neuronal activity were partially restored following knockdown of voltage-gated sodium channel $\beta 2(\mathrm{Nav} \beta 2)$, encoded by SCN2B, in APP/PS1 mice (7). These results suggested that increased SCN2B levels may be responsible for aging-associated cognitive decline. However, the regulators of ectopic SCN2B expression in the aging brain remain unknown.

Previous studies revealed that aging induces various changes in the expression of multiple genes at the single-neuron level, which may be attributed to the regulation by microRNAs (miRNAs/miR). For example, Kadakkuzha et al (8) demonstrated that 1083 Expressed Sequence Tags (ESTs) were differentially regulated in mature and older R15 neurons; French et al, found many genes overexpressed were downregulated with age in layer 2/3 glutamatergic neurons (9). miRNAs are small non-coding RNA molecules measuring 20-22 nucleotides in length. By binding to the 3'untranslated region (3'-UTR) of a target gene, miRNAs induce post-transcriptional regulation of gene expression and silence the expression of protein-coding genes, which are involved in cell apoptosis, death and proliferation (10-14). Recent studies confirmed that abnormal expression of multiple miRNAs is involved in the progression of neurodegenerative diseases (15-17).

It was previously demonstrated that the expression of miR-9 and miR-9* in the hippocampi of SAMP8 mice was decreased compared with that in the age-matched control senescence-accelerated mouse-resistant 1 (SAMR1) mice, and SCN2B was one of the predicted target genes of miR-9 (18). It was also observed that miR-9 and miR-9* participated in brain aging by targeting the mitogen-activated protein kinase kinase kinase 3 and cyclin dependent kinase (CDK) inhibitor $1 \mathrm{C}$ genes in SAMP8 mice (18). Based on the aforementioned data, it was inferred that miRNAs may contribute to the regulation of the age-associated changes in SCN2B expression. If such a regulatory mechanism exists, miRNAs may serve a role in the progression of cognitive decline via targeting the SCN2B gene. An understanding of the regulatory mechanism underlying the abnormal expression of SCN2B in the aging process is required to fully elucidate the potential role and underlying molecular mechanism of SCN2B in the cognitive decline associated with the aging process.

The aim of the present study was to investigate whether miRNAs participate in the pathological process of cognitive decline in the aging brain by regulating the expression of SCN2B. The results may help identify a miRNA-based therapy that may lead to an effective and innovative pharmaceutical treatment strategy in the future.

\section{Materials and methods}

Ethics statement. Animal use and care were performed in accordance with the Guide for the Care and Use of Laboratory Animals published by the US National Institutes of Health (19) and the Care and Use of Experimental Animals Guidelines established by the Ministry of Medicine of Yunnan, China. The ethics committee of Kunming Medical University approved the study protocol (permit no. km-edw-2013118).

Mouse preparation. Male SAMP8 and SAMR1 mice, aged 4 (SAMP8, n=5; SAMR1, n=3) and 12 (SAMP8, n=5; SAMR1, n=3) months, respectively, were purchased from the Tianjin Traditional Chinese Medical College and maintained at the Kunming Institute of Zoology. The mice were kept at $21-23^{\circ} \mathrm{C}$ with a 12:12 h light/dark cycle, and food and drinking water were available ad libitum. The mice were sacrificed following anesthesia by $2.5 \%$ inhaled isoflurane and their tissues were harvested rapidly and placed on ice.

SAMP8 is an autogenic senile strain characterized by early cognitive impairment and age-associated deterioration of learning and memory; the SAMR1 strain was used as the control. SAMP8 has become a major biogerontological resource in studies investigating aging.

Samples of the prefrontal cortex and hippocampus were collected from 5 4-month-old SAMP8 and 5 12-month-old SAMP8 mice. The age-matched SAMR1 mice were used as control $(n=3)$. Tissues were then collected and RNA was isolated using TRIzol ${ }^{\circledR}$ reagent (Gibco; Thermo Fisher Scientific, Inc.). Total RNA from each sample was quantified by the NanoDrop ND-1000 (NanoDrop Technologies) and RNA integrity was assessed by standard denaturing agarose gel electrophoresis. Briefly, $10 \mu \mathrm{g}$ of RNA sample per lane was prepared in $2 \mu \mathrm{l} 10 \mathrm{X}$ MOPS (0.2 mol/1 MOPS pH 7.0; $20 \mathrm{mmol} / 1$ sodium acetate; $10 \mathrm{mmol} / 1$ EDTA pH 8.0; Beyotime Institute of Biotechnology), $4 \mu 113.3 \mathrm{~mol} / \mathrm{l}$ formaldehyde, $10 \mu \mathrm{l}$ $10 \mathrm{~mol} / \mathrm{l}$ formamide and $1 \mu 1200 \mu \mathrm{g} / \mathrm{ml}$ ethidium bromide (EB; Beyotime Institute of Biotechnology) in a nucleic acid-freed $1.5 \mathrm{ml}$ tube. The RNA sample was incubated at $55^{\circ} \mathrm{C}$ for $60 \mathrm{~min}$, cooled at $4^{\circ} \mathrm{C}$ for $20 \mathrm{~min}$ and centrifuged at $1,000 \mathrm{x} \mathrm{g}$ for $5 \mathrm{~min}$. The sample was then mixed with $2 \mu \mathrm{l}$ BeyoRed DNA loading buffer (D0072; Beyotime Institute of Biotechnology) with 0.05 U RNase Inhibitor (R0102-2 kU; Beyotime Institute of Biotechnology). The RNA was analyzed by electrophoresis using a $1.5 \%$ agarose gel stained with EB with $1 \mathrm{X}$ MOPS buffer and visualized using an ultraviolet Bio-Gel imager (Bio-Rad Laboratories, Inc.). Total intact RNA with 18S and $28 \mathrm{~S}$ ribosomes from each sample was used for labeling and array hybridization.

RNA labeling and array hybridization. The miRNA microarray experiments were performed using a Mouse miRNA Expression Array V3.0 chip (Aksomics, Inc.) to scan the differentially expressed miRNAs in the prefrontal cortex or hippocampal tissues of SAMP8 and SAMR1 mice aged 4 and 12 months, respectively. Total RNA was extracted by the TRIzol ${ }^{\circledR}$ reagent (Gibco; Thermo Fisher Scientific, Inc.) and quantified for purity and concentration using a NanoDrop 1000 spectrophotometer (Thermo Fisher Scientific, Inc.). Following hybridization, the different fluorescence intensities of miRNA were obtained by image scanning. Differentially expressed genes were identified through fold-change filtering. Hierarchical clustering was performed using the Agilent GeneSpring GX software (Agilent Technologies, Inc.).

Reverse transcription-quantitative polymerase chain reaction (RT-qPCR). miRNAs were quantified using RT-qPCR. RNA from cells and tissue samples were prepared using TRIzol ${ }^{\circledR}$ reagent (Gibco; Thermo Fisher Scientific, Inc.) according to the manufacturer's protocol. cDNA was synthesized from total RNA using gene-specific primers using the TaqMan MicroRNA Assay (Applied Biosystems; Thermo Fisher 
Scientific, Inc.) according to the manufacturer's instructions. Concentrations of RNA samples were determined using a NanoDrop ND-1000 spectrophotometer (NanoDrop Technologies). The $20 \mu \mathrm{l}$ PCR reaction contained $10 \mu \mathrm{l} 2 \mathrm{X}$ PCR Master Mix (Roche Diagnostics), $0.25 \mu \mathrm{l}$ primer (10 pmol/l), $1 \mu \mathrm{l}$ cDNA template and $8.5 \mu \mathrm{l}$ PCR nuclease-free water. The primer sequences were as follows: U6 forward, 5'-CTCGCT TCGGCAGCACA-3' and reverse, 5'-AACGCTTCACGAATT TGCGT-3'; miR-34a-5p forward, 5'-TCGGATCTTCCAAGG CTC-3' and reverse, 5'-GCTGTCAACGATACGCTACGT AACG-3'; miR-449a forward, 5'-AATCCGTCTCCCTAA CTCTAGGCTT-3' and reverse, 5'-GCTGTCAACGATACG CTACGTAACG-3'; miR-9 forward, 5'-CTCTCCGGATAT CCGTTGCTCCGGTCTC-3' and reverse, 5'-GCTGTCAAC GATACGCTACGTAACG-3' (Takara Biotechnology Co., Ltd.). The thermocycling conditions were as follows: $95^{\circ} \mathrm{C}$ for $3 \mathrm{~min}$, followed by 40 cycles of $94^{\circ} \mathrm{C}$ for $35 \mathrm{sec}, 56.5^{\circ} \mathrm{C}$ for $30 \mathrm{sec}$ and $72^{\circ} \mathrm{C}$ for $30 \mathrm{sec}$. Samples were normalized to the housekeeping gene U6. Relative gene expression was determined using the $2^{-\Delta \Delta \mathrm{Cq}}$ method (20) and the experiment was repeated three times.

Cell culture. The primary mouse hippocampal neuron culture was performed by using previously described methods $(21,22)$. Briefly, neonatal mice (0 days) were decapitated following anesthesia with isoflurane, and the hippocampi were carefully separated. The hippocampi were digested with $0.05 \%$ trypsin (Gibco; Thermo Fisher Scientific, Inc.) at $37^{\circ} \mathrm{C}$ for $10 \mathrm{~min}$, then centrifuged at $1,000 \mathrm{rpm}$ for $10 \mathrm{~min}$ at room temperature following trypsin digestion. Neurons were resuspended in complete culture medium containing DMEM-high glucose (HyClone; GE Healthcare Life Sciences), 15\% fetal calf serum (Gibco; Thermo Fisher Scientific, Inc.) and 1\% penicillin/streptomycin. Cells at the required density $\left(5 \times 10^{5}\right.$ cells $\left./ \mathrm{ml}\right)$ were seeded onto the PPL-coated culture plate. The cells were cultured in a humidified incubator at $37^{\circ} \mathrm{C}$ with $5 \% \mathrm{CO}_{2}$. Thereafter, the culture media from each well were replaced with fresh composite media every third day.

Bioinformatics predictions. To identify potential miRNAs that may target SCN2B, multiple computational algorithms, including TargetScan (23-27), miRanda (28) and Diana microT v5.0 $(29,30)$, were used for bioinformatics predictions as previously described (31). The potential miRNAs were predicted according to the sequence of the SCN2B 3'-UTR.

Cell transfection. The primary neurons were plated in 6-well culture plates at a density of $2.0 \times 10^{6}$ per plate for RIP-Chip transfections, as described previously $(10,32)$. Briefly, artificial 'Pre-miRNA' referent tommu-miR-449a was designed and purchased from Ambion; Thermo Fisher Scientific, Inc. At $24 \mathrm{~h}$ after seeding, cells were transfected with $10 \mu \mathrm{l}$ of $25 \mathrm{nM}$ each 'Pre-miRNA', or negative control (NC) miRNA (Ambion; Thermo Fisher Scientific, Inc.) using RNAiMAX (Invitrogen; Thermo Fisher Scientific, Inc.) according to the manufacturer's protocol. The sense sequences were as follows: mmu-miR-449a: GGCAGUGUAUUGUUAGCUG, and NC miRNA: AGUACUGCUUACGAUACGG. Following transfection, the cells were cultured for $48 \mathrm{~h}$ prior to further experimentation.
Northern blot analysis. To evaluate the effectiveness and specificity of miRNA transfections, Northern blots were employed according to a previously described protocol (33). Northern blot analyses were performed using RNA isolated from cultured neurons $48 \mathrm{~h}$ after transfection with miRNAs.

RNA immunoprecipitation chip (RIP-Chip). A total of 3 miRNAs, miR-9, miR-449a and miR-34a-5p, each of which was predicted by all 3 software programs and were downregulated in the SAMP8 mouse brain, were selected for further validation among the numerous miRNAs identified. The anti-AGO co-immunoprecipitation (co-IP) and downstream microarray analyses (RIP-Chip) were employed to confirm the results of computationally-predicted miRNAs targeting SCN2B.

Co-IP of microribonucleoparticles (miRNPs). The RIP-Chip co-IP assay protocol employed in the present study has been previously described in detail $(32,34)$. Briefly, cells were harvested $48 \mathrm{~h}$ after transfection. Cell lysates were subjected to preclearance by incubation with pre-blocked protein $\mathrm{G}$ beads (Invitrogen; Thermo Fisher Scientific, Inc.) at $4^{\circ} \mathrm{C}$ for 60 min. Co-IP with either Ago (cat. no. K004319P; Beijing Solarbio Science and Technology Co., Ltd.)-protein G beads or non-immune mouse serum (Pierce; Thermo Fisher Scientific, Inc.)-protein $\mathrm{G}$ beads, was then performed at $4^{\circ} \mathrm{C}$ for $90 \mathrm{~min}$ using lysate aliquots. Following co-IP, the beads were washed 3-5 times with lysis buffer at room temperature. Beads and lysates were then subjected to DNase treatment by gently shaking and incubating at $37^{\circ} \mathrm{C}$ for 20 min with $250 \mu 1$ DNA digestion solution (Pierce; Thermo Fisher Scientific, Inc.). The immunoprecipitated RNA and total RNA from lysates were then extracted using TRIzol LS (Invitrogen; Thermo Fisher Scientific, Inc.) as described previously (33).

Post-Co-IP microarray analysis. Microarray analysis of RNAs isolated via co-IP was performed using a Mouse $12 \times 135 \mathrm{~K}$ Gene Expression Array manufactured by Roche NimbleGen, Inc. A total of 8 biological replicates from 3 individual experiments were performed for each transfection condition. For gene array, slides were scanned at $5 \mu \mathrm{m} /$ pixel resolution using an Axon GenePix 4000B scanner (Molecular Devices, LLC) piloted by GenePix Pro 6.0 software (Axon; Molecular Devices, LLC). The scanned images were then imported into NimbleScan software (v.2.5; Roche NimbleGen, Inc.) for grid alignment and expression data analysis. Expression data were subjected to quantile normalization and the Robust Multichip Average (RMA) algorithm included in the NimbleScan software. All gene level files were imported into Agilent GeneSpring GX software (v.11.5.1; Agilent Technologies, Inc.) for further analysis. Differentially expressed genes were identified through fold-change filtering. Hierarchical clustering was performed using the Agilent GeneSpring GX 11.0 software (Agilent Technologies, Inc.). The functions of the differentially expressed miRNAs were analyzed by Gene Ontology (GO) $(35,36)$ and Kyoto Encyclopedia of Genes and Genomes (KEGG) (37-39) databases.

RNA preparation and quantification. Following careful rinsing in cooled PBS, cells were homogenized on ice using 
TRIzol (Invitrogen; Thermo Fisher Scientific, Inc.). Total RNA was isolated using TRIzol, according to the manufacturer's protocol. RNA quality and quantity were measured using an ND-1000 NanoDrop spectrophotometer (NanoDrop Technologies; Thermo Fisher Scientific, Inc.), and RNA integrity was determined by gel electrophoresis. An equal amount of RNA $(4 \mu \mathrm{g})$ was used for each experiment.

RT-qPCR analysis was performed according to the protocol described previously to detect the expression levels of the SCN2B gene (32). $\beta$-actin was used as a reference and subtracted for net changes. Gene primers were synthesized by Takara Bio, Inc. Each data point represents the results of 3 technical replicates. The primer sequences were as follows: SCN2B forward, 5'-CTACACCGTGAACCACAAGCA-3' and reverse, 5 '-GACCACAGCCAGGAAACCC-3'; $\beta$-actin forward, 5'-ATATCGCTGCGCTGGTCGTC-3' and reverse, 5'-AGGATGGCGTGAGGGAGAGC-3'.

Dual-luciferase reporter gene assay. The potential target sites for miR-449a on the mouse SCN2B mRNA 3'-UTR seed regions, including both wild-type (wt) and mutant (mut) sequences, were cloned. The artificially cloned sequences were inserted downstream of the luciferase reporter gene, pGL3 (Guangzhou RiboBio Co., Ltd.), to generate the SCN2B 3'-UTR-wt and SCN2B 3'-UTR-mut vectors, as described previously $(40,41)$. Briefly, 293T cells (purchased from Institute of Biochemistry and Cell Biology, Shanghai, China) were seeded in 96-well plates and co-transfected with $100 \mathrm{ng} / \mathrm{ml}$ of each pGL3-SCN2B 3'-UTR-wt or -mut vector and $35 \mathrm{nM}$ miR-449a mimics or NC (Guangzhou RiboBio Co., Ltd.). Lipofectamine ${ }^{\circledR}$ 2000 (Invitrogen; Thermo Fisher Scientific, Inc.) was used as the transfection reagent. The effects of miR-449a treatment on luciferase activity were measured at $48 \mathrm{~h}$ post-transfection. The firefly and Renilla luciferase activities were separately measured using a Dual Luciferase Reporter Assay System kit (Promega Corporation) and a Tecan M200 luminescence reader (Tecan Group, Ltd.) according to the manufacturer's instructions. The relative transcriptional activity was normalized to Renilla luciferase activity.

Cell treatment. To determine whether miR-449a contributed to aging-associated pathological events in SAMP8 mice by targeting SCN2B, miR-449a overexpression and miR-449a inhibition was established in cultured primary neurons. A lentiviral system was employed for miR-449a/SCN2B overexpression (plenti-miR-449a/plenti-SCN2B; Guangzhou RiboBio Co., Ltd.), while miRNA sponge technology was used to inhibit miR-449a activity (miR-449a-sponge) as described previously $(40,42)$. The blank plasmid lemiR, referred to as lemiR, and the non-binding sponge sequence, referred to as CX-control, were used as controls. The expression of SCN2B was inhibited by transfection with the pNX-U6 plasmid (Takara Biotechnology, Co., Ltd.) ligated with small interfering RNA (siRNA) targeting SCN2B (SCN2B-siRNA; $20 \mathrm{nM}$; Guangzhou RiboBio Co., Ltd.), with the pNX-U6 plasmid alone serving as a blank control (empty-siRNA) (43). Additionally, plenti-miR-449a was also co-transfected with plenti-SCN2B using the aforementioned lentiviral overexpression system, and was termed 'plenti-miR-449a + plenti-SCN2B'. The plenti-miR-449a co-transfected with
lemiR served as a control, named 'plenti-miR-1 + SCN2B control'. Similarly, the miR-449a-sponge was co-transfected with the SCN2B-siRNA plasmid, or with the empty-siRNA to serve as a control, and referred to as 'miR-449a-sponge + SCN2B-siRNA' and 'miR-449a-sponge + empty-siRNA', respectively. Lipofectamine ${ }^{\circledR} 2000$ (Invitrogen; Thermo Fisher Scientific, Inc.) was used as the transfection reagent.

The miR-449a expression and SCN2B mRNA and protein levels were evaluated at $48 \mathrm{~h}$ after transfection. Then the neurons were photographed under a fluorescence LEICA DMI6000B microscope (LAS AF system; Leica Microsystems $\mathrm{GmbH}$ ) at x200 magnification. The effects of miR-449a overexpression and inhibition on neuronal growth were additionally evaluated by measuring the axon length, areas of neurons and cell numbers using Image-Pro Plus 6.0 software (Media Cybernetics, Inc.).

Western blot analysis. Western blot analysis was used to evaluate the SCN2B protein expression levels in primary neurons transfected with miR-449a overexpression or sponge vectors, according to a previously described protocol $(6,43)$. Briefly, cell samples were lysed on ice for $30 \mathrm{~min}$ in CytoBuster Protein Extraction Buffer (Novagen; Merck KGaA), and $50 \mu \mathrm{g}$ protein was used for $10 \%$ SDS-PAGE. The proteins were then transferred to a nitrocellulose membrane and blocked using TBS $+100 \%$ Tween-20 (TBST) containing 5\% non-fat milk powder for $1 \mathrm{~h}$ at room temperature. The membrane was subsequently incubated with goat anti-SCN2B (1:800; cat. no. ASC-007; Alomone Labs) and anti-GAPDH (1:500; cat. no. sc-47724; Santa Cruz Biotechnology, Inc.) antibodies at $4^{\circ} \mathrm{C}$ overnight. Following washing in TBST, the membrane was incubated with horseradish peroxidase-conjugated anti-mouse secondary antibodies (1:1,000; cat. no. sc-516132; Santa Cruz Biotechnology, Inc.) for $2 \mathrm{~h}$ at $25^{\circ} \mathrm{C}$. The bands were visualized by an electrochemiluminescence technique (Best-Bio Co., Ltd.). Images were captured using the JS Gel Imaging System (Shanghai Peiqing Science \& Technology Co., Ltd.), and gray densities were calculated using SensiAnsys software (version JS-680D; Shanghai Peiqing Science \& Technology Co., Ltd.).

Statistical analyses. Statistical analyses were performed using SPSS v.16.0 (SPSS, Inc.). Data are presented as the mean \pm standard deviation. The statistical significance among multiple groups was evaluated by one-way ANOVA followed by Bonferroni's post hoc test, whereas comparisons between two groups were performed using Student's t-test. $\mathrm{P}<0.05$ was considered to indicate a statistically significant difference.

\section{Results}

miRNA microarray analysis. In order to elucidate the regulatory mechanism underlying the increased expression of SCN2B with aging, miRNA microarray analysis was performed to compare the miRNA expression profiles in the prefrontal cortex and hippocampus between the SAMP8 and SAMR1 mice aged 4 and 12 months, respectively. Microarray analysis identified multiple differentially expressed miRNAs in the prefrontal cortex and hippocampus of SAMP8 mice compared with the SAMR1 mice $(\mathrm{P}<0.05$; Fig. 1A). The data suggested that expressional alteration of miRNAs may 
A

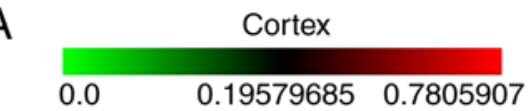

Hippocampus

$0.0 \quad 0.35472172 \quad 2.2154646$
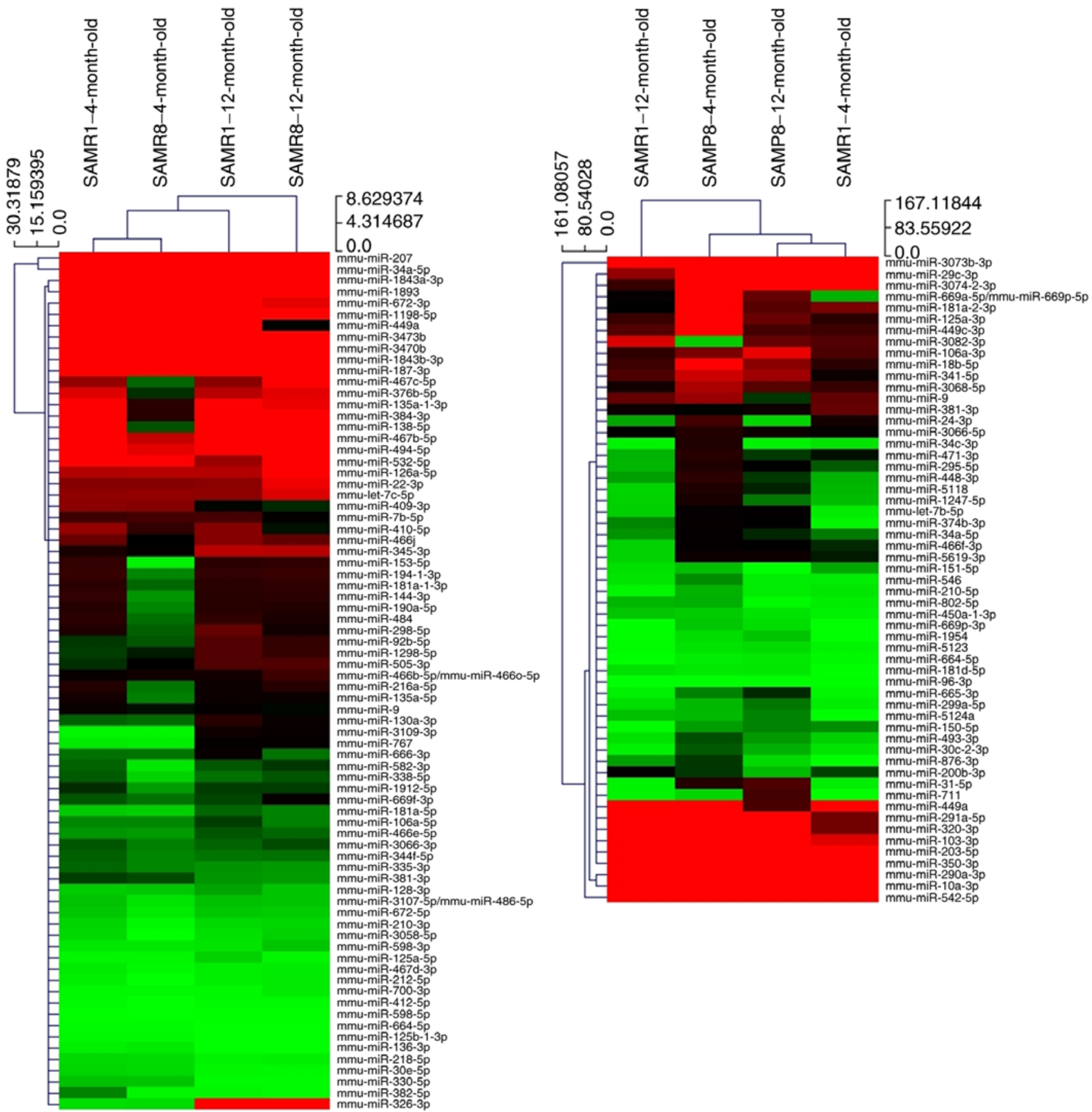

Figure 1. miRNA microarray profiling and validation. (A) Heatmap demonstrating differentially expressed miRNAs, analyzed by hierarchical clustering for all targets. Red indicates high relative expression, and green indicates low relative expression. Fold-change filtering was used to indicate the differentially expressed miRNAs between 4- and 12-month-old mice. The threshold was fold change $\geq 2.0$.

contribute to the SCN2B regulation associated with aging in SAMP8 mice. Based on these data, the present study then focused on the abnormally downregulated miRNAs in SAMP8 mice at 12 months compared with the age-matched control mice. In order to identify the potential miRNAs that may target SCN2B, the present study focused on the downregulated miRNAs, which were also predicted by the computational algorithms TargetScan (23-27), miRanda (28) and Diana microT v5.0 $(29,30)$ with the presence of 8 -mer site in the 3'-UTR of the SCN2B gene; miR-449a, miR-34a-5p and miR-9a were identified for subsequent analyses.

RT-qPCR was utilized to validate the expression levels of miR-449a, miR-34a-5p and miR-9a mRNA in the prefrontal cortex and hippocampi of the SAMP8 mice. No significant differences in the expression levels of all 3 miRNAs were observed at the age of 4 months compared with the SAMR1 
B
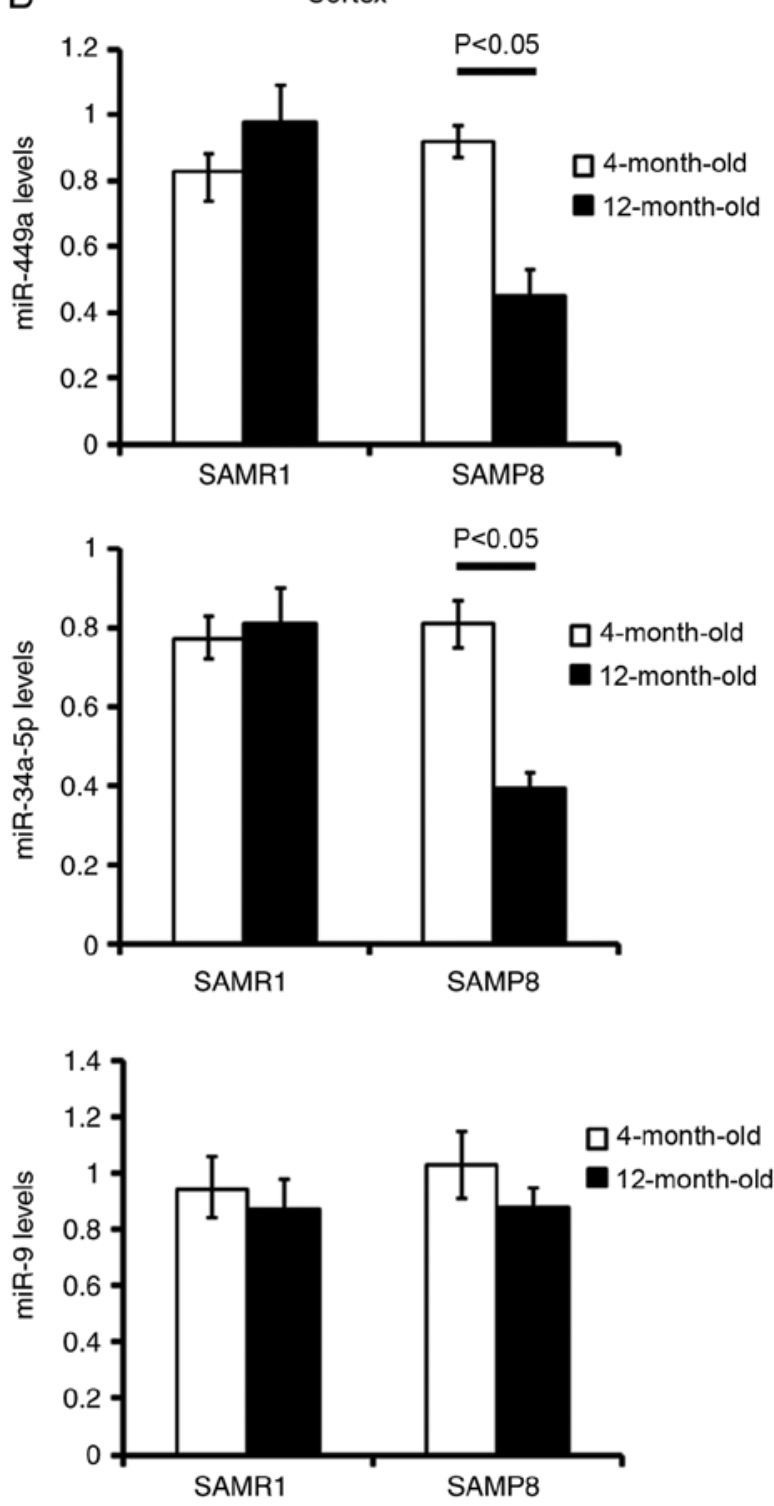
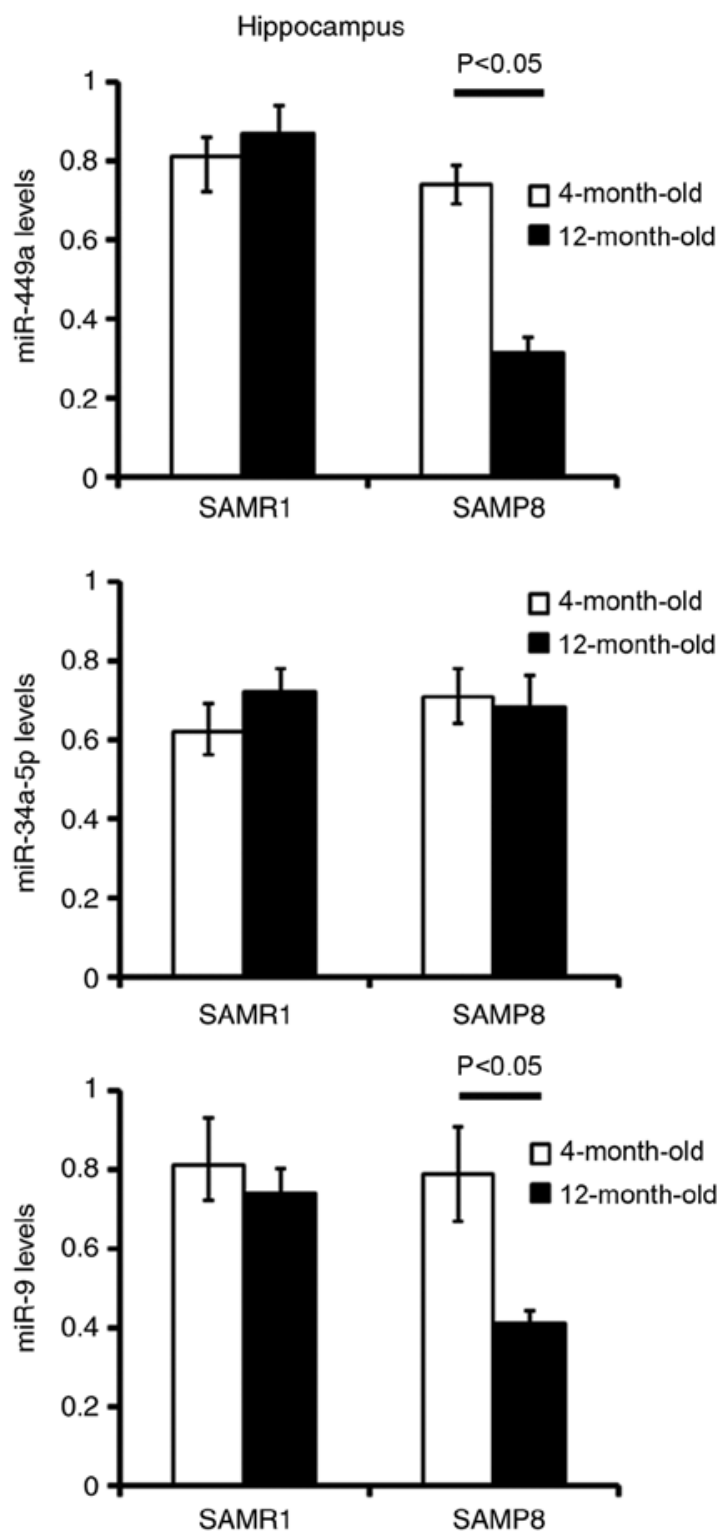

Figure 1. Continued. (B) Quantitative polymerase chain reaction analysis revealed that the expression levels of miR-449a, miR-34-5p and miR-9 in the prefrontal cortex or/and hippocampus of SAMP8 mice were significantly decreased compared with the age-matched SAMR1 controls. SAMP8, senescence-accelerated mice; SAMR1, normal aging mice (senescence-accelerated mouse resistant).

mice (Fig. 1B). However, miR-449a was identified to be significantly decreased in both the prefrontal cortex and hippocampus, miR-34a-5p was decreased in the prefrontal cortex, while miR-9a was decreased in the hippocampus of 12-month-old SAMP8 mice compared with the age-matched SAMR1 controls (Fig. 1B).

These results indicated that the downregulation of miR-449a, miR-34a-5p and miR-9 may be involved in the aging process of the prefrontal cortex or hippocampus of SAMP8 mice, which may be mediated by regulating their target genes.

Dual-luciferase reporter assay indicates $S C N 2 B$ as a target of mirR-449a. To identify the miRNAs that regulate SCN2B, a dual-luciferase analysis was performed. SCN2B 3'-UTR-wt and SCN2B 3'-UTR-mut were co-transfected with miR-449a, miR-9, miR-34a-5p mimics or NC control. The results revealed that the miR-449a mimic decreased the luciferase activity of the SCN2B 3'-UTR-wt cells, but exerted no effect on the SCN2B
3'-UTR-mut cells, as compared with the miR-NC-treated group (Fig. 2A). Furthermore, as demonstrated in Fig. 2B and C, no significant changes in the luciferase activities of the SCN2B 3'-UTR-wt or SCN2B 3'-UTR-mut cells following transfection with miR-9 or miR-34a-5p, compared with the matched NC controls. These results indicated that miR-449a may directly regulate SCN2B 3'-UTR by acting on the seed region 'CAC UGCCG'.

SCN2B is highly enriched in miR-449a-Ago-miRNPs complex. Northern blots (Fig. 3A) were performed using RNA isolated from neurons $48 \mathrm{~h}$ after transfection with miR-449a, which was performed to examine the effectiveness and specificity of miRNA transfections. The results demonstrated that transfected miR-449a was successfully incorporated into the neurons.

To verify that miR-449a targeted SCN2B, an RIP-Chip analysis was performed to validate the putative miRNA targets identified by co-IP miRNPs following the transfec- 


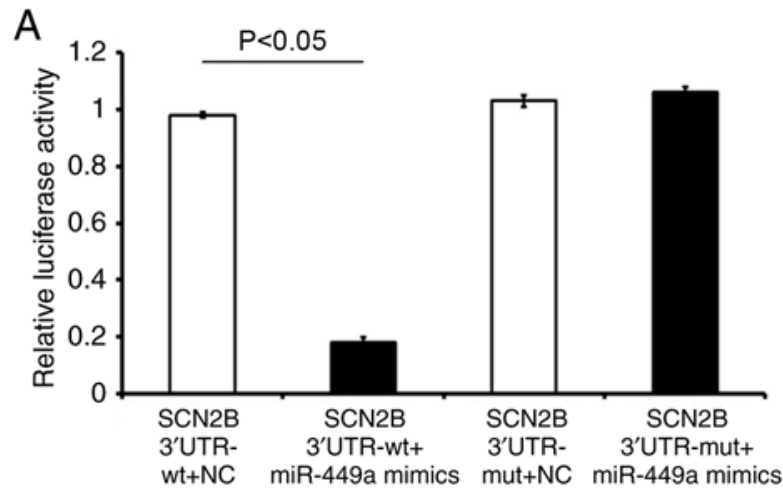

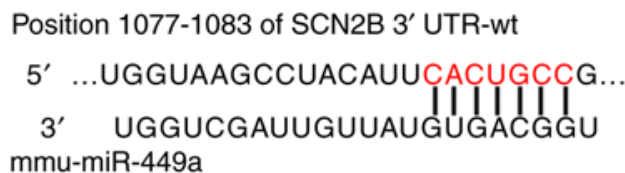

Position 1077-1083 of SCN2B 3' UTR-mut

5'...UGGUAAGCCUACAUUGUGACGGG...

3' UGGUCGAUUGUUAUGUGACGGU

mmu-miR-449a
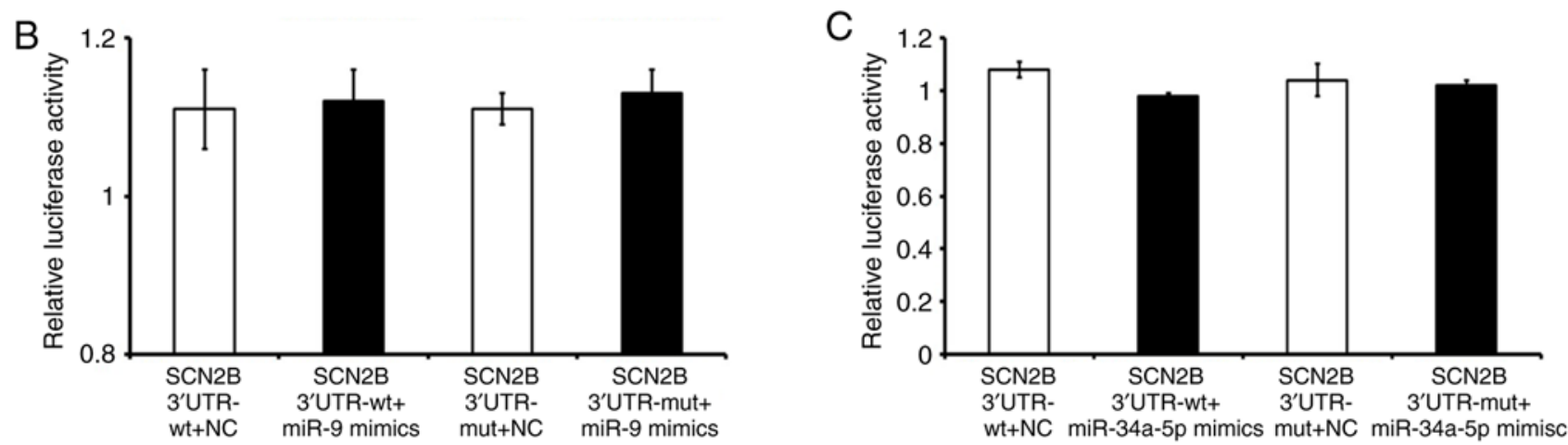

Figure 2. Identification of the 3'-UTR seed region of SCN2B mRNA targeted by miR-449a. A dual-luciferase activity assay for SCN2B 3'UTR-wt or SCN2B 3'UTR-mut detected firefly and luciferase activities following transfection with (A) miR-449a, (B) miR-9, (C) miR-34a-5p mimic or miR-NC. (A): Relative luciferase activity of miR-449a mimics co-transfected with SCN2B 3'UTR-wt or 3'UTR-mut (left panel) and seed regions of SCN2B gene directly regulated by miR-449a (right panel). NC, negative control; UTR, untranslated region; wt, wild-type; mut, mutant; SCN2B, sodium channel voltage-gated beta 2.

tion of miR-449a in primary hippocampal cells of mice. The primary hippocampal cells incubated with Ago antibody were treated with miR-449a probe, and target genes bound to the Ago-miRNPs complex were detected. Large amounts of enriched SCN2B mRNA were detected in the co-precipitated miR-449a-Ago-miRNPs complex. As demonstrated in Fig. 3B and C, the target mRNA, which was highly enriched with Ago-miRNPs, was confirmed to be SCN2B. This result represents important evidence that miR-449a may target the SCN2B mediated by Ago-miRNPs in cultured hippocampal neurons in vitro.

$S C N 2 B$ is a valid target of miR-449a. In neurons overexpressing miR-449a, treatment with plenti-miR-449a downregulated the expression of SCN2B mRNA by $75 \%$. Treatment with plenti-SCN2B partially restored SCN2B expression compared with the CX-control (Fig. 4A). By contrast, inhibition of miR-449a increased SCN2B mRNA expression by 2.1-fold in miR-449a-sponge-transfected neurons compared with the CX-control (Fig. 4B). SCN2B-siRNA treatment partially reversed the miR-449a inhibition-induced effects. Similar changes in SCN2B protein levels were also observed in neurons following transfection with various chemicals (Fig. 4C and D). These results confirmed SCN2B as a target gene of miR-449a. Considering the potential roles of SCN2B in the aging-associated cognitive deficit $(5,6)$, the effects of SCN2B and miR-449a on the neurite growth of hippocampal neurons in mice was evaluated.

Treatment with plenti-miR-449a increased the mean neurite length of primary cultured neurons compared with the matched
lemiR-treated control (Fig. 5). By contrast, miR-449a-sponge transfection induced shorter extension compared with that of the CX-control (Fig. 5). The extension length was partially decreased in plenti-miR-449a following plenti-SCN2B transfection when compared with the plenti-miR-449a + lemiR SCN2B-treated controls (Fig. 5). SCN2B-siRNA partially restored the decreased neurite extension induced by the miR-449a-sponge (miR-449a-sponge + SCN2B-siRNA vs. miR-449a-sponge + empty-siRNA). These results suggested that miR-449a may serve a key role in neuron growth and the associated progression of brain aging by targeting SCN2B.

\section{Discussion}

In the present study, miRNAs expression profiles in the prefrontal cortex and hippocampi of 4- and 12-month SAMP8 mice and age-matched SAMR1 controls were detected by miRNA microarray. The SAMP8 strain is an animal model of rapid aging, and is ideal for studying brain aging and dementia (44). SAMP8 mice not only have pathological characteristics associated with $\mathrm{AD}$, such as excessive phosphorylation of tau protein and $\mathrm{A} \beta$ deposition, but also exhibit similar behavioral characteristics to those of elderly humans $(45,46)$. The present study revealed that numerous miRNAs detected in the cortex and hippocampus of aged SAMP8 mice exhibited differences in expression levels from the aged-matched SAMR1 controls. It was therefore inferred that the downregulated miRNAs may contribute to the upregulated genes associated with brain aging. Following consolidation of the results of miRNA microarray analysis and the predicted lists of target genes obtained by bioinformatics analysis, 3 miRNAs 

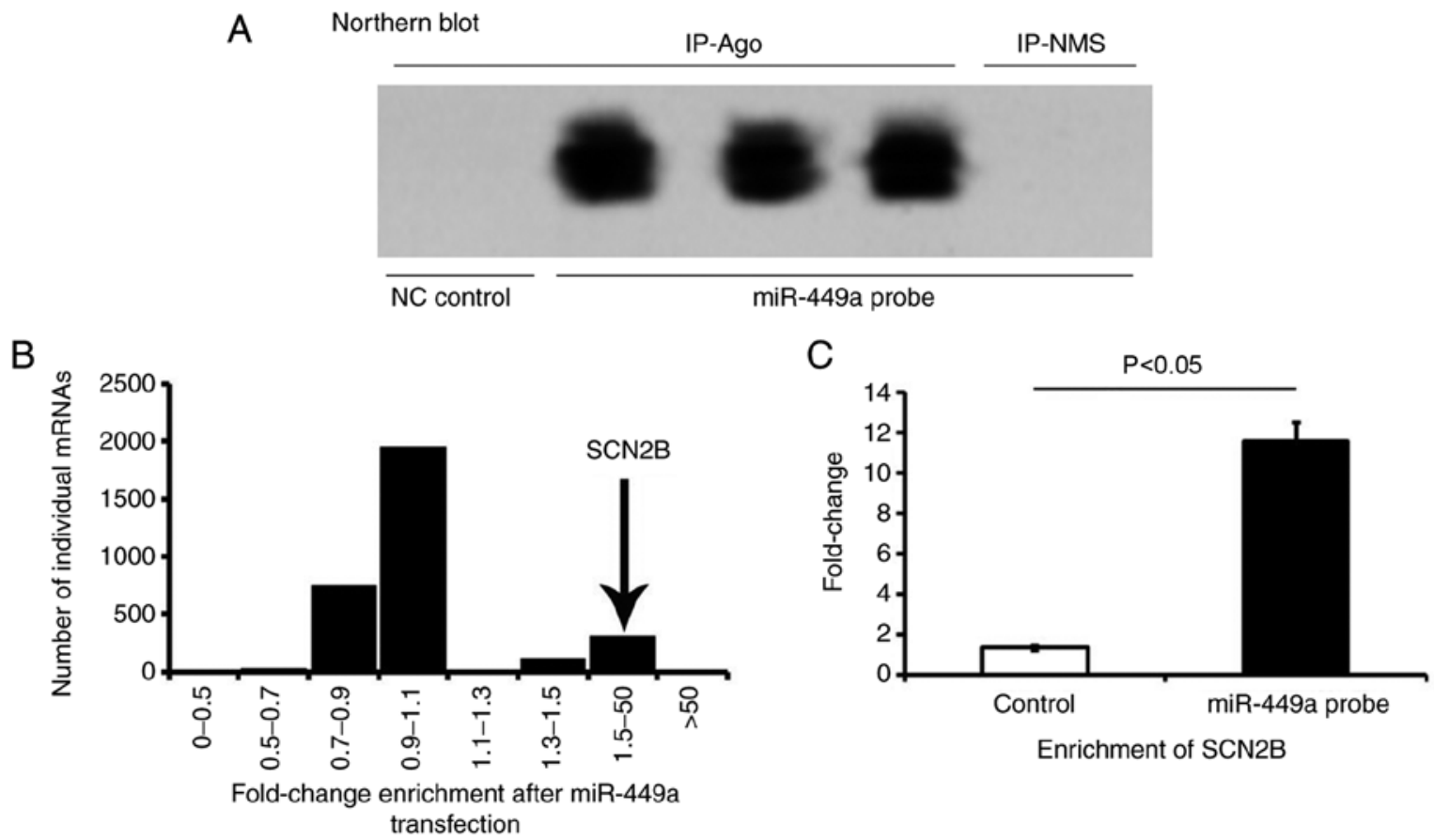

Figure 3. SCN2B is highly enriched in miR-449a-Ago-miRNPs complex. (A) Northern blot analysis of miRNPs isolated following miR-449a transfection. The results revealed that miR-449a was specifically recruited to miRNPs following miRNA transfection. (B) Enrichment of target genes of miR-449a-Ago-miRNPs complex in primary hippocampal neurons $(\mathrm{n}=3,953)$. Relative SCN2B enrichment in miRNPs consistently increased by $>10$-fold following miR-449a transfection. (C) Compared with the control group, the enrichment of SCN2B following miR-449a probe treatment was significant. SCN2B, sodium channel voltage-gated $\beta 2$; miR, microRNA; miRNPs, microribonucleoparticles; IP-Ago, anti-Ago immunoprecipitation.

were selected for subsequent analysis: miR-449a, miR-34a-5p and miR-9. RT-qPCR analysis verified the results of the miRNA chip assay, which demonstrated decreased levels of miR-449a, miR-34a-5p and miR-9 in the frontal cortex or hippocampus of 12-month old SAMP8 mice. The subsequent dual-luciferase reporter assay confirmed that miR-449a targets SCN2B by binding to the 3'-UTR of the SCN2B seed region 'CACUGCCA'. Anti-Ago co-IP combined with Affymetrix microarray analyses were utilized in the present study as described previously (32), which verified that the target mRNA highly enriched in the miR-449a-Ago-miRNPs complex was SCN2B. These results represent important evidence of the direct regulation of SCN2B by miR-449a in cultured hippocampal neurons. The knockout and overexpression experiments demonstrated that SCN2B was a valid target of miR-449a. It was also revealed that miR-449a upregulation or SCN2B downregulation promoted the extension of the processes of cultured neurons. Co-transfection with SCN2B overexpression or siRNA vectors partially neutralized the effects induced by miR-449a upregulation or downregulation. These data suggest that miR-449a may serve an important role in neuron growth and associated progression of aging by targeting SCN2B.

The crucial role of miR-449a in various diseases, such as breast and pancreatic cancer, osteosarcoma, gastric carcinoma, viral hepatitis and hypoxia-induced conditions has been well-documented (47-51). Previous studies also verified numerous target genes regulated by miR-449a, including CDKs (52-54), hepatocyte growth factor/c-Met receptor system (HGF/MET) (55) and synaptotagmin 1 (Syt1) (56), among others. miR-449a was demonstrated to be involved in the development and progression of AD through a variety of molecular mechanisms by regulating target genes. CDKs have been confirmed to be downregulated in AD (57). HGF/MET was able to induce dendritic arborization and synaptogenesis when stimulated by N-hexanoic-Tyr-Ile-(6) aminohexanoic amide and it served a role in facilitating the formation of new functional synaptic connections and augmenting memory consolidation in animal models of AD (58). The downregulation of $\mathrm{HGF} / \mathrm{MET}$ in the brain functional regions of patients with AD was associated with a poor prognosis (59). Syt1, as a novel amyloid precursor protein-interacting protein, promotes $\mathrm{A} \beta$ generation and regulates the $\mathrm{A} \beta$ level of the synapse, serving a potentially important role in the pathogenesis of AD $(60,61)$. The expression of Syt1 was significantly downregulated in cerebrospinal fluid and brain tissue samples of human patients with early-onset AD (62). Therefore, by regulating a series of target molecules, such as CDKs (57) and/or Syt1 (60-62), miR-449a may be involved in the synaptogenesis of neurons and the regulation of $\mathrm{A} \beta$ levels.

The results of the present study demonstrated that miR-449a levels decrease with aging in mice and that the overexpression of $\mathrm{miR}-449 \mathrm{a}$ promotes the extension of neuronal processes, suggesting that miR-449a may serve an important role in the occurrence and development of neurodegenerative diseases. SCN2B, covalently linked to a subunit, is enriched in the central nervous system, and has been well characterized as a cell-cell adhesion protein $(63,64)$. Nav2 $\beta$ serves a key role in neuropathic pain $(65,66)$, cardiac arrhythmias (67), Brugada syndrome (68), epilepsy (69), multiple sclerosis (70) and perineural invasion in prostate cancer (71). Studies have suggested that $\operatorname{Nav} \beta 2$ is a substrate of $\beta$-site APP-cleaving enzyme 1 (7,72). Nav $\beta 2$ knockdown improved cognition and restored sodium current density in hippocampal neurons and neuronal activity in APP/PS1 mice (7), whereas 

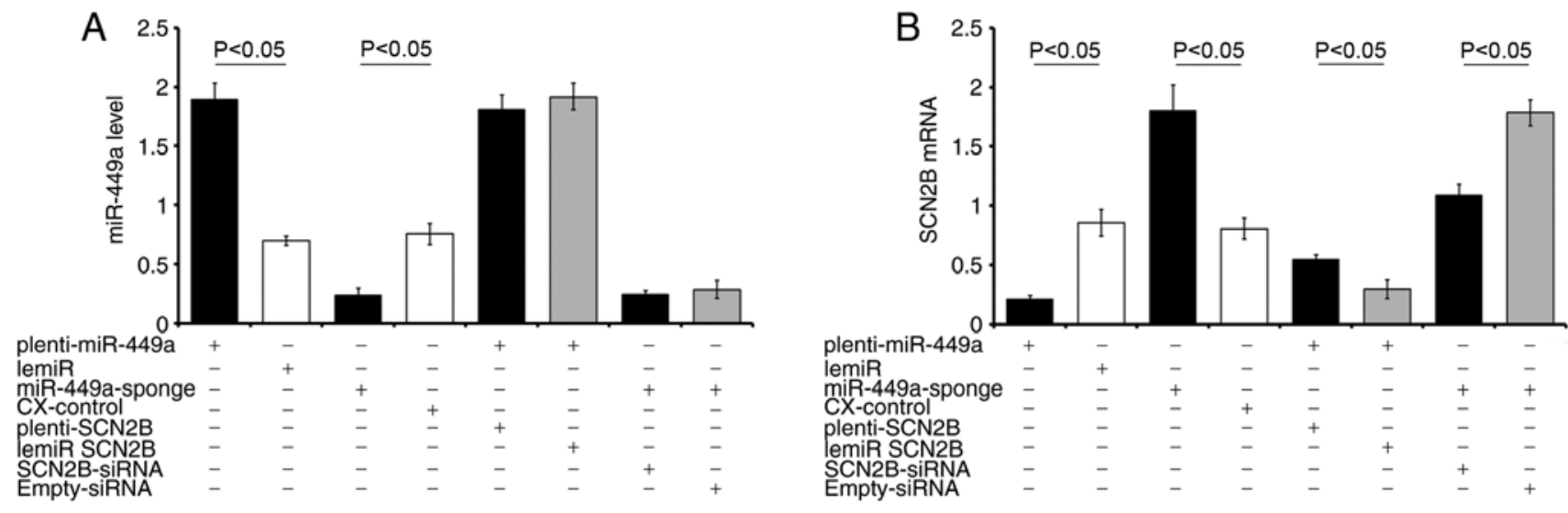

C

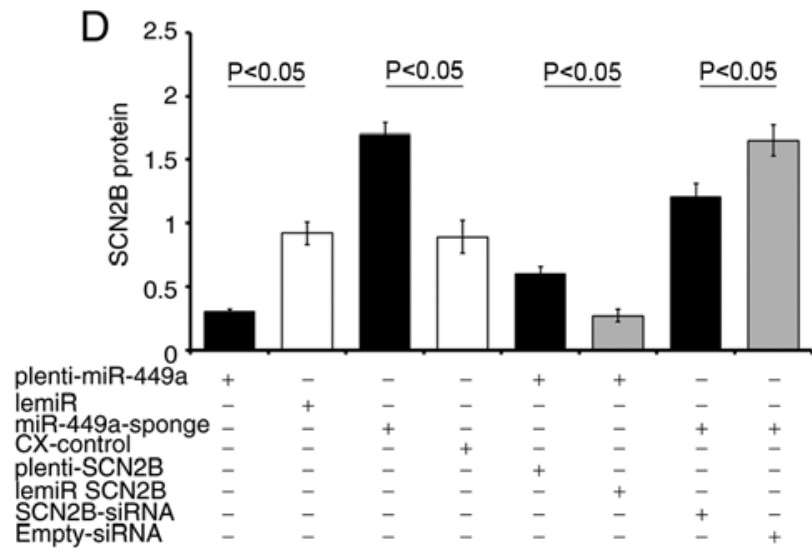

Figure 4. SCN2B is regulated by miR-449a in hippocampal neurons. (A) miR-449a expression in primary cultured hippocampus neurons following different treatments. (B) SCN2B mRNA expression in primary cultured hippocampal neurons following different treatments. (C) Representative western blot analysis for SCN2B protein expression. (D) SCN2B protein levels in primary cultured hippocampal neurons following different treatments. All data are representative of 5 independent experiments and are presented as the mean \pm standard deviation $(n=5)$. SCN2B, sodium channel voltage-gated $\beta 2$; miR, microRNA; lemiR, blank plasmid lemiR; CX-control, non-binding sponge sequence; siRNA, small interfering RNA.
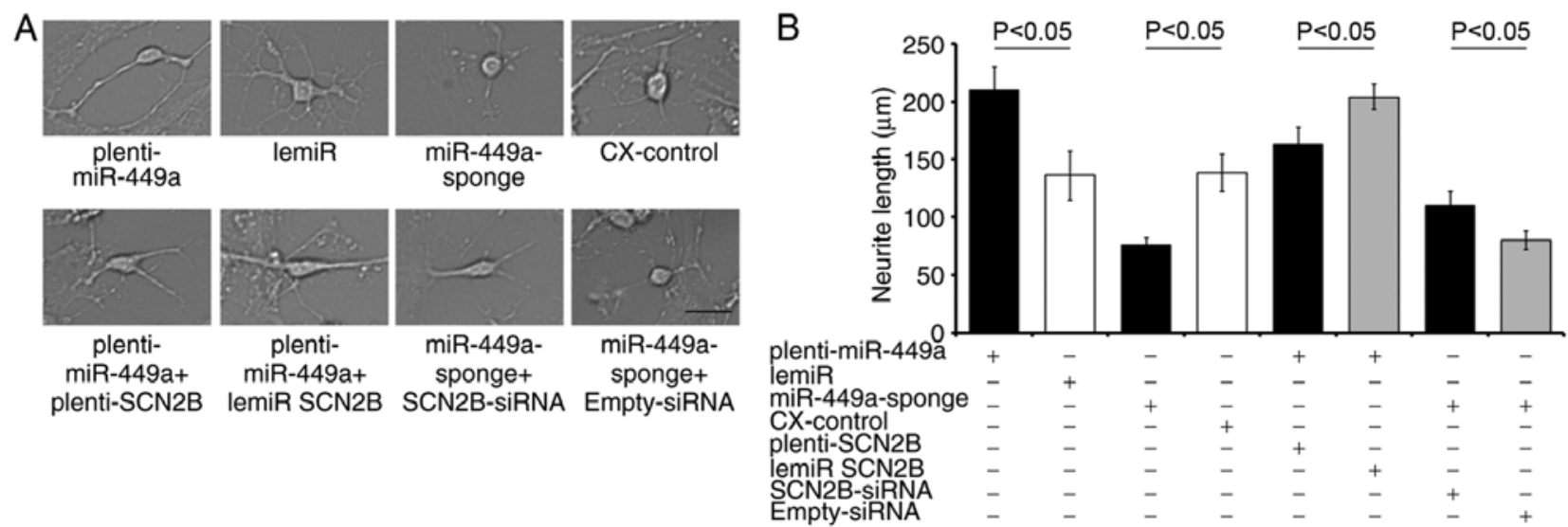

Figure 5. miR-449a alters neurite extension by targeting SCN2B. (A) Micrograph of primary cultured hippocampal cells with various treatments. Magnification, x200. Scale bar, $100 \mu \mathrm{m}$. (B) The mean neurite lengths were quantitated. miR, microRNA; SCN2B, sodium channel voltage-gated $\beta 2$; lemiR, blank plasmid lemiR; CX-control, non-binding sponge sequence; siRNA, small interfering RNA.

presenilin/secretase-mediated cleavage of the Nav $\beta 2$-CTF (Nav 32 -C-terminal fragment) regulates cell adhesion and migration (64). SCN2B knockdown significantly decreases the expression of amyloid precursor protein and the deposition of $A \beta_{41,42}$ in the hippocampus of transgenic mice. SCN2B may be involved in the pathogenesis of AD by changing the stability and excitability of sodium ion channels. Experiments conducted in the present study verified that SCN2B is a valid target of miR-449a, and that miR-449a may regulate the process of brain aging by targeting SCN2B.

In conclusion, the present study demonstrated that the age-associated increase in SCN2B is associated with the regulation of miR-449a, which may serve a crucial role in brain aging by targeting SCN2B. These data may suggest a novel pathogenetic mechanism and potential candidate for the treatment of brain aging. 


\section{Acknowledgements}

Not applicable.

\section{Funding}

The present study was supported by the National Natural Science Foundation of China (grant nos. 81960210, 81701212, 81560238 and 31560279), the Yunnan Applied Basic Research Foundation of Yunnan Province in China (grant no. 2016FB123), the Foundation of Science and Technology Innovative Team Building of Kunming Medical University (grant no. CXTD201807) and the Medical Reserve Talents Cultivation Project of the Health and Family Planning Commission of Yunnan Province (grant no. H-2017026).

\section{Availability of data and materials}

The data sets generated and analyzed during the present study are available from the corresponding author on reasonable request.

\section{Authors' contributions}

YBX, YH, SJ, MNL and YXT designed the study, analyzed the data and prepared the manuscript. YXT, MNL, SL, BC and TH conducted mouse experiments, cell culture, cell transfection and cell treatments. YBX, YH, MNL and SJ performed RNA labeling and array hybridization, bioinformatics predictions, western blots, reverse transcription-quantitative PCR, Northern blot experiments and analysis. BC, LZ, TH, RMa and RMe conducted RIP-Chip, Co-IP, dual-luciferase, Northern blot experiments and analysis. All authors were substantially involved in the research, acquisition of data, analysis and manuscript preparation. All authors read and approved the final manuscript.

\section{Ethics approval and consent to participate}

Animal use and care were performed in accordance with the Guide for the Care and Use of Laboratory Animals published by the US National Institutes of Health (19) and the Care and Use of Experimental Animals Guidelines established by the Ministry of Medicine of Yunnan, China. The Ethics Committee of Kunming Medical University approved the present study (permit no. km-edw-2013118).

\section{Patient consent for publication}

Not applicable.

\section{Competing interests}

The authors declare that they have no competing interests.

\section{References}

1. Barzilai N, Cuervo AM and Austad S: Aging as a biological target for prevention and therapy. JAMA 320: 1321-1322, 2018.

2. Fang EF, Scheibye-Knudsen M, Jahn HJ, Li J, Ling L, Guo H, Zhu X, Preedy V, Lu H, Bohr VA, et al: A research agenda for aging in China in the 21st century. Ageing Res Rev 24: 197-205, 2015.
3. Lu T, Pan Y, Kao SY, Li C, Kohane I, Chan J and Yankner BA: Gene regulation and DNA damage in the ageing human brain. Nature 429: 883-891, 2004.

4. Dhar Malhotra J, Chen C, Rivolta I, Abriel H, Malhotra R, Mattei LN, Brosius FC, Kass RS and Isom LL: Characterization of sodium channel alpha- and beta-subunits in rat and mouse cardiac myocytes. Circulation 103: 1303-1310, 2001.

5. Hao C, Yanbin X, Jia L, Ping D and Wang TJ: The expression and changes of SCN2B mrna in frontal lobe and hippocampus of senescence-accelerated mouse. Chin J Neuroanat 23: 662-665, 2007.

6. XiYang YB, Wang YC, Zhao Y, Ru J, Lu BT, Zhang YN, Wang NC, Hu WY, Liu J, Yang JW, et al: Sodium channel voltage-gated beta 2 plays a vital role in brain aging associated with synaptic plasticity and expression of COX5A and FGF-2. Mol Neurobiol 53: 955-967, 2016.

7. Hu T, Xiao Z, Mao R, Chen B, Lu MN, Tong J, Mei R, Li SS, Xiao ZC, Zhang LF and Xiyang YB: Nav $\beta 2$ knockdown improves cognition in APP/PS1 mice by partially inhibiting seizures and APP amyloid processing. Oncotarget 8: 99284-99295, 2017.

8. Kadakkuzha BM, Akhmedov K, Capo TR, Carvalloza AC, Fallahi M and Puthanveettil SV: Age-associated bidirectional modulation of gene expression in single identified R15 neuron of Aplysia. BMC Genomics 14: 880, 2013.

9. French L, Ma T, Oh H, Tseng GC and Sibille E: Age-related gene expression in the frontal cortex suggests synaptic function changes in specific inhibitory neuron subtypes. Front Aging Neurosci 9: 162, 2017.

10. Zhang ZB, Tan YX, Zhao Q, Xiong LL, Liu J, Xu FF, Xu Y, Bobrovskaya L, Zhou XF and Wang TH: miRNA-7a-2-3p inhibits neuronal apoptosis in oxygen-glucose deprivation (OGD) model. Front Neurosci 13: 16, 2019.

11. Nohata N, Sone Y, Hanazawa T, Fuse M, Kikkawa N, Yoshino H, Chiyomaru T, Kawakami K, Enokida H, Nakagawa M, et al: miR-1 as a tumor suppressive microRNA targeting TAGLN2 in head and neck squamous cell carcinoma. Oncotarget 2: 29-42, 2011.

12. Bartel DP: MicroRNAs: Genomics, biogenesis, mechanism, and function. Cell 116: 281-297, 2004.

13. Fabian MR and Sonenberg N: The mechanics of miRNA-mediated gene silencing: A look under the hood of miRISC. Nat Struct Mol Biol 19: 586-593, 2012.

14. Son YH, Ka S, Kim AY and Kim JB: Regulation of adipocyte differentiation via MicroRNAs. Endocrinol Metab (Seoul) 29: 122-135, 2014.

15. Saraiva C, Esteves M and Bernardino L: MicroRNA: Basic concepts and implications for regeneration and repair of neurodegenerative diseases. Biochem Pharmacol 141: 118-131, 2017.

16. Lin Y, Liang X, Yao Y, Xiao H, Shi Y and Yang J: Osthole attenuates APP-induced Alzheimer's disease through up-regulating miRNA-101a-3p. Life Sci 225: 117-131, 2019.

17. Wang M, Qin L and Tang B: MicroRNAs in Alzheimer's disease. Front Genet 10: 153, 2019.

18. Liu W, Liu C, Yin B and Peng XZ: Functions of miR-9 and miR-9* during Aging in SAMP8 mice and their possible mechanisms. Zhongguo Yi Xue Ke Xue Yuan Xue Bao 37: 253-258, 2015.

19. National Research Council (US) Committee for the Update of the Guide for the Care and Use of Laboratory Animals: Guide for the Care and Use of Laboratory Animals, 8th edition. National Academies Press (US), Washington, DC, 2011.

20. Livak KJ and Schmittgen TD: Analysis of relative gene expression data using real-time quantitative PCR and the 2(-Delta Delta C(T)) Method. Methods 25: 402-408, 2001.

21. Shen Q, Wang Y, Dimos JT, Fasano CA, Phoenix TN, Lemischka IR, Ivanova NB, Stifani S, Morrisey EE and Temple S: The timing of cortical neurogenesis is encoded within lineages of individual progenitor cells. Nat Neurosci 9: 743-751, 2006.

22. Zhang F, Qian X, Qin C, Lin Y, Wu H, Chang L, Luo C and Zhu D: Phosphofructokinase-1 negatively regulates neurogenesis from neural stem cells. Neurosci Bull 32: 205-216, 2016.

23. Agarwal V, Bell GW, Nam J and Bartel DP: Predicting effective microRNA target sites in mammalian mRNAs. Elife 4, 2015.

24. García DM, Baek D, Shin C, Bell GW, Grimson A and Bartel DP: Weak seed-pairing stability and high target-site abundance decrease the proficiency of 1sy- 6 and other microRNAs. Nat Struct Mol Biol 18: 1139-1146, 2011.

25. Friedman RC, Farh KK, Burge CB and Bartel DP: Most mammalian mRNAs are conserved targets of microRNAs. Genome Res 19: 92-105, 2009. 
26. Grimson A, Farh KK, Johnston WK, Garrett-Engele P, Lim LP and Bartel DP: MicroRNA targeting specificity in mammals: Determinants beyond seed pairing. Molecular Cell 27: 91-105, 2007.

27. Lewis BP, Burge CB and Bartel DP: Conserved seed pairing, often flanked by adenosines, indicates that thousands of human genes are microRNA targets. Cell 120: 15-20, 2005.

28. John B, Enright AJ, Aravin A, Tuschl T, Sander C and Marks DS: Human MicroRNA targets. PLoS Biol 2: e363, 2004.

29. Paraskevopoulou MD, Georgakilas G, Kostoulas N, Vlachos IS Vergoulis T, Reczko M, Filippidis C, Dalamagas T and Hatzigeorgiou AG: DIANA-microT web server v5.0: Service integration into miRNA functional analysis workflows. Nucleic Acids Res 41 (Web Server Issue): W169-W173, 2013.

30. Reczko M, Maragkakis M, Alexiou P, Grosse I and Hatzigeorgiou AG: Functional microRNA targets in protein coding sequences. Bioinformatics 28: 771-776, 2012.

31. Krek A, Grün D, Poy MN, Wolf R, Rosenberg L, Epstein EJ, MacMenamin P, da Piedade I, Gunsalus KC, Stoffel M and Rajewsky N: Combinatorial microRNA target predictions. Nat Genet 37: 495-500, 2005.

32. Wang WX, Wilfred BR, Hu Y, Stromberg AJ and Nelson PT: Anti-Argonaute RIP-Chip shows that miRNA transfections alter global patterns of mRNA recruitment to microribonucleoprotein complexes. RNA 16: 394-404, 2010.

33. Wang WX, Wilfred BR, Baldwin DA, Isett RB, Ren $N$, Stromberg A and Nelson PT: Focus on RNA isolation: Obtaining RNA for microRNA (miRNA) expression profiling analyses of neural tissue. Biochim Biophys Acta 1779: 749-757, 2008.

34. Nelson PT, De Planell-Saguer M, Lamprinaki S, Kiriakidou M, Zhang P, O'Doherty U and Mourelatos Z: A novel monoclonal antibody against human Argonaute proteins reveals unexpected characteristics of miRNAs in human blood cells. RNA 13 $1787-1792,2007$

35. Ashburner M, Ball CA, Blake JA, Botstein D, Butler $\mathrm{H}$ Cherry JM, Davis AP, Dolinski K, Dwight SS, Eppig JT, et al: Gene ontology: Tool for the unification of biology. The Gene Ontology Consortium. Nat Genet 25: 25-29, 2000.

36. The Gene Ontology Consortium: The gene ontology resource: 20 years and still GOing strong. Nucleic Acids Res 47 (D1) D330-D338, 2019.

37. Zhu KP,Zhang CL, Ma XL, Hu JP, Cai T and Zhang L: Analyzing the interactions of mRNAs and ncRNAs to predict competing endogenous RNA networks in osteosarcoma chemo-resistance. Mol Ther 27: 518-530, 2019.

38. Lai J, Wang H, Pan Z and Su F: A novel six-microRNA-based model to improve prognosis prediction of breast cancer. Aging (Albany NY) 11: 649-662, 2019.

39. Lee WJ, Moon J, Jeon D, Shin YW, Yoo JS, Park DK, Lee ST, Jung KH, Park KI, Jung KY, et al: Possible epigenetic regulatory effect of dysregulated circular RNAs in Alzheimer's disease model. Sci Rep 9: 11956, 2019.

40. Hu T, Chang YF, Xiao Z, Mao R, Tong J, Chen B, Liu GC, Hong Y, Chen HL, Kong SY, et al: miR-1 inhibits progression of high-risk papillomavirus-associated human cervical cancer by targeting G6PD. Oncotarget 7: 86103-86116, 2016.

41. Ebert MS, Neilson JR and Sharp PA: MicroRNA sponges: Competitive inhibitors of small RNAs in mammalian cells. Nat Methods 4: 721-726, 2007.

42. Bhalala OG, Pan L, Sahni V, McGuire TL, Gruner K, Tourtellotte WG and Kessler JA: microRNA-21 regulates astrocytic response following spinal cord injury. J Neurosci 32: 17935-17947, 2012.

43. Hu T, Lu MN, Chen B, Tong J, Mao R, Li SS, Dai P, Tan YX and Xiyang YB: Electro-acupuncture-induced neuroprotection is associated with activation of the IGF-1/PI3K/Akt pathway following adjacent dorsal root ganglionectomies in rats. Int $\mathrm{J} \mathrm{Mol}$ Med 43: 807-820, 2019.

44. Li D, Ke Y, Zhan R, Liu C, Zhao M, Zeng A, Shi X, Ji L, Cheng S, $\mathrm{Pan} \mathrm{B}$, et al: Trimethylamine-N-oxide promotes brain aging and cognitive impairment in mice. Aging Cell 17: e12768, 2018

45. Akiguchi I, Pallàs M, Budka $\mathrm{H}$, Akiyama $\mathrm{H}$, Ueno $\mathrm{M}$, Han J, Yagi H, Nishikawa T, Chiba Y, Sugiyama H, et al: SAMP8 mice as a neuropathological model of accelerated brain aging and dementia: Toshio Takeda's legacy and future directions. Neuropathology 37: 293-305, 2017.

46. Manich G, Mercader C, del Valle J, Duran-Vilaregut J, Camins A, Pallàs M, Vilaplana J and Pelegrí C: Characterization of amyloid- $\beta$ granules in the hippocampus of SAMP8 mice. J Alzheimers Dis 25: 535-546, 2011
47. Tormo E, Ballester S, Adam-Artigues A, Burgués O, Alonso E, Bermejo B, Menéndez S, Zazo S, Madoz-Gúrpide J, Rovira A, et al: The miRNA-449 family mediates doxorubicin resistance in triple-negative breast cancer by regulating cell cycle factors. Sci Rep 9: 5316, 2019.

48. Li F, Liang J and Bai L: MicroRNA-449a functions as a tumor suppressor in pancreatic cancer by the epigenetic regulation of ATDC expression. Biomed Pharmacother 103: 782-789, 2018.

49. Chen J, Zhou J, Chen X, Yang B, Wang D, Yang P, He X and Li H: miRNA-449a is downregulated in osteosarcoma and promotes cell apoptosis by targeting BCL2. Tumour Biol 36: 8221-8229, 2015.

50. Sarma NJ, Tiriveedhi V, Crippin JS, Chapman WC and Mohanakumar T: Hepatitis $\mathrm{C}$ virus-induced changes in microRNA 107 (miRNA-107) and miRNA-449a modulate CCL2 by targeting the interleukin- 6 receptor complex in hepatitis. J Virol 88: 3733-3743, 2014.

51. Muth M, Hussein K, Jacobi C, Kreipe $\mathrm{H}$ and Bock O: Hypoxia-induced down-regulation of microRNA-449a/b impairs control over targeted SERPINE1 (PAI-1) mRNA-a mechanism involved in SERPINE1 (PAI-1) overexpression. J Transl Med 9: 24, 2011.

52. Lize M,Pilarski S and Dobbelstein M: E2F1-inducible microRNA $449 \mathrm{a} / \mathrm{b}$ suppresses cell proliferation and promotes apoptosis. Cell Death Differ 17: 452-458, 2010.

53. Feng $\mathrm{M}$ and $\mathrm{Yu} \mathrm{Q}: \mathrm{miR}-449$ regulates CDK-Rb-E2F1 through an auto-regulatory feedback circuit. Cell Cycle 9: 213-214, 2010.

54. Ma LP, Li N, He XJ and Zhang Q: miR-449b and miR-34c on inducing down-regulation of cell cycle-related proteins and cycle arrests in SKOV3-ipl cell, an ovarian cancer cell line. Beijing Da Xue Xue Bao Yi Xue Ban 43: 129-133, 2011 (In Chinese).

55. Buurman R, Gürlevik E, Schäffer V, Eilers M, Sandbothe M, Kreipe H, Wilkens L, Schlegelberger B, Kühnel F and Skawran B: Histone deacetylases activate hepatocyte growth factor signaling by repressing microRNA-449 in hepatocellular carcinoma cells. Gastroenterology 143: 811-820.e15, 2012.

56. Yang B, Dai JX, Pan YB, Ma YB and Chu SH: Identification of biomarkers and construction of a microRNA-mRNA regulatory network for ependymoma using integrated bioinformatics analysis. Oncol Lett 18: 6079-6089, 2019.

57. Lim AC and Qi RZ: Cyclin-dependent kinases in neural development and degeneration. J Alzheimers Dis 5: 329-335, 2003

58. Wright JW and Harding JW: The brain hepatocyte growth Factor/c-Met receptor system: A new target for the treatment of Alzheimer's disease. J Alzheimers Dis 45: 985-1000, 2015.

59. Hamasaki H, Honda H, Suzuki SO, Hokama M, Kiyohara Y, Nakabeppu Y and Iwaki T: Down-regulation of MET in hippocampal neurons of Alzheimer's disease brains. Neuropathology 34: 284-290, 2014.

60. Gautam V, D'Avanzo C, Berezovska O, Tanzi RE and Kovacs DM: Synaptotagmins interact with APP and promote $\mathrm{A} \beta$ generation. Mol Neurodegener 10: 31, 2015.

61. Kuzuya A, Zoltowska KM, Post KL, Arimon M, Li X, Svirsky S, Maesako M, Muzikansky A, Gautam V, Kovacs D, et al: Identification of the novel activity-driven interaction between synaptotagmin 1 and presenilin 1 links calcium, synapse, and amyloid beta. BMC Biol 14: 25, 2016.

62. Davidsson P, Jahn R, Bergquist J, Ekman R and Blennow K: Synaptotagmin, a synaptic vesicle protein, is present in human cerebrospinal fluid: A new biochemical marker for synaptic pathology in Alzheimer disease? Mol Chem Neuropathol 27: 195-210, 1996.

63. Isom LL: The role of sodium channels in cell adhesion. Front Biosci 7: 12-23, 2002.

64. Kim DY, Ingano LA, Carey BW, Pettingell WH and Kovacs DM: Presenilin/gamma-secretase-mediated cleavage of the voltage-gated sodium channel beta2-subunit regulates cell adhesion and migration. J Biol Chem 280: 23251-23261, 2005.

65. Pertin M, Ji RR, Berta T, Powell AJ, Karchewski L, Tate SN, Isom LL, Woolf CJ, Gilliard N, Spahn DR and Decosterd I: Upregulation of the voltage-gated sodium channel beta2 subunit in neuropathic pain models: Characterization of expression in injured and non-injured primary sensory neurons. J Neurosci 25 : 10970-10980, 2005.

66. Lopez-Santiago LF, Pertin M, Morisod X, Chen C, Hong S, Wiley J, Decosterd I and Isom LL: Sodium channel beta2 subunits regulate tetrodotoxin-sensitive sodium channels in small dorsal root ganglion neurons and modulate the response to pain. J Neurosci 26: 7984-7994, 2006 
67. Bao Y, Willis BC, Frasier CR, Lopez-Santiago LF, Lin X, Ramos-Mondragón R, Auerbach DS, Chen C, Wang Z, Anumonwo J, et al: $\mathrm{Scn} 2 \mathrm{~b}$ deletion in mice results in ventricular and atrial arrhythmias. Circ Arrhythm Electrophysiol 9: pii: e003923, 2016.

68. Riuró H, Beltran-Alvarez P, Tarradas A, Selga E, Campuzano O, Vergés M, Pagans S, Iglesias A, Brugada J, Brugada P, et al: A missense mutation in the sodium channel $\beta 2$ subunit reveals $\mathrm{SCN} 2 \mathrm{~B}$ as a new candidate gene for Brugada syndrome. Hum Mutat 34: 961-966, 2013.

69. Wang JW, Shi XY, Kurahashi H, Hwang SK, Ishii A, Higurashi N, Kaneko S and Hirose S; Epilepsy Genetic Study Group Japan: Prevalence of SCN1A mutations in children with suspected Dravet syndrome and intractable childhood epilepsy. Epilepsy Res 102: 195-200, 2012.

70. O'Malley HA, Shreiner AB, Chen GH, Huffnagle GB and Isom LL: Loss of $\mathrm{Na}^{+}$channel beta2 subunits is neuroprotective in a mouse model of multiple sclerosis. Mol Cell Neurosci 40: $143-155,2009$.
71. Jansson KH, Castillo DG, Morris JW, Boggs ME, Czymmek KJ, Adams EL, Schramm LP and Sikes RA: Identification of beta-2 as a key cell adhesion molecule in PCa cell neurotropic behavior: A novel ex vivo and biophysical approach. PLoS One 9: e98408, 2014.

72. Huth T, Schmidt-Neuenfeldt K, Rittger A, Saftig P, Reiss K and Alzheimer C: Non-proteolytic effect of beta-site APP-cleaving enzyme 1 (BACE1) on sodium channel function. Neurobiol Dis 33: 282-289, 2009 .

This work is licensed under a Creative Commons Attribution-NonCommercial-NoDerivatives 4.0 International (CC BY-NC-ND 4.0) License. 